\title{
MASS MOVEMENTS OF AN ALPINE ROCK GLACIER
}

\author{
R.Boesch, C. Graf
}

Swiss Federal Research Institute of Snow, Forst and Landscape WSL, 8903 Birmensdorf, Switzerland

\{ruedi.boesch, christoph.graf\}@wsl.ch

KEY WORDS: Natural hazards monitoring, change detection in natural environments

\begin{abstract}
:
Rock glaciers, tonguelike bodies consisting of angular rock debris frozen in interstitial ice, may flow with velocities varying from a few centimeter up to several meters per year. Recent ground warming may generate an accelerated slope movement related to permafrost creep.

Newer generations of commercial off-the-shelf drones like DJI Mavic are cost-effective, lightweight and still have a sufficient pay load reserve for flights at 2800 m.a.s.l. This allows that a two men crew can carry the necessary reference and drone equipment in a high alpine environment and a flight campaign can be conducted within one day.

Using different cameras with similar optical resolution allows to generate DSMs with comparable accuracy. The DSM resolution should be $10 \mathrm{~cm}$ or better to achieve robust results. Motion tracking of rock glacier with tie point matching algorithms SIFT or SURF combined with an appropriate filter method allows to distinguish different movement patterns within local neighborhood. Compared to point-wise GPS-based methods or image-based cross-correlation approaches, tie point matching allows to detect inhomogeneous movement patterns, which are typical for rock glaciers in a high alpine environment.
\end{abstract}

\section{INTRODUCTION}

Rock glaciers may flow with velocities varying from a few centimeters up to several meters per year. Recent ground warming may generate an accelerated slope movement related to permafrost creep.

Topography, rock size distribution, hidden ice bodies, local climate are among several factors which have a strong influence on the velocity and are typically non-uniform within a rock glacier in high alpine areas (Muller et al. 2016).

Motion detection in alpine environments is often based on GPS point measurements of installed observation networks (Ghirlanda et al. 2016). But for many remote locations, the logistic effort of a permanent ground-based observation network is often not feasible. Remote sensing using UAV-based photogrammetry is therefore an attractive alternative, which requires no previous installed equipment and allows to observe an area of interest without any gaps.

\section{DATA ACQUISITION}

\subsection{Test Site}

The Jegi rock glacier in the Valais Alps west of the Jegihorn in the Saas valley consists of a rooting zone (2700 - $2800 \mathrm{~m}$ a.s.1.) and a body down to an upper front $(2550 \mathrm{~m})$, which overflows a second tongue $150 \mathrm{~m}$ long below. Destabilization processes of the active rock glacier with a total length of $720 \mathrm{~m}$ and a width of $100-150 \mathrm{~m}$ have been observed since at least the 1950s and are expressed in partly strongly increased velocities of movement. Currently, the upper body - between 2670 and 2550 $\mathrm{m}$ - can be regarded as destabilized: Movements are above average and many fissures and cracks are opening; the upper front has been moving about $10 \mathrm{~m} /$ year since 2015 (Ghirlanda, Braillard, Delaloye, Kummert and Staub 2016). Falling loose material from the front represents potential source material for future debris flows in the Teiffu Grabu, a steep torrent that flows into the main valley south of Saas-Balen.

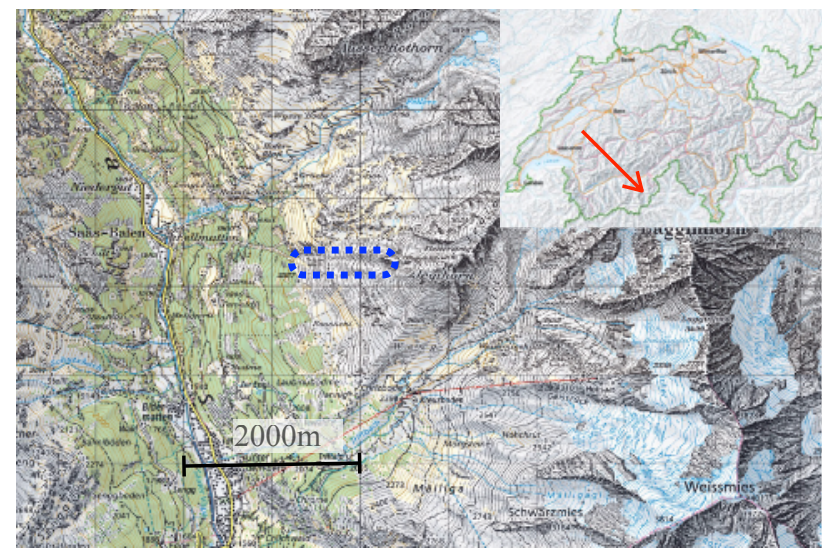

Figure 1. Location of test site at Jegihorn, Valais, Switzerland.

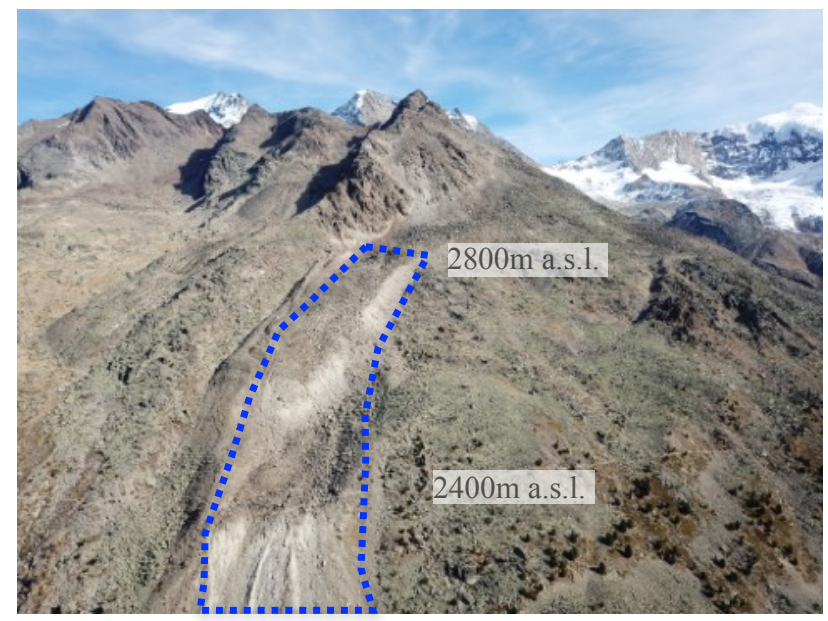

Figure 2. Rock glacier at the test site Jegihorn. 


\subsection{UAV Platforms}

3 drone flight campaigns were executed at the end of the summer in the years 2016, 2017 and 2018.

\begin{tabular}{|l|r|c|r|r|r|}
\hline Year & Camera & Images & $\begin{array}{l}\text { GSD } \\
\text { [cm] }\end{array}$ & GCP & \multicolumn{1}{|c|}{$\begin{array}{c}\text { GCP-Error } \\
\text { [m] }\end{array}$} \\
\hline 2016 & Sony & 388 & 2.3 & 10 & 0.33 \\
\hline 2017 & Sony & 332 & 2.8 & 22 & 0.31 \\
\hline 2018 & DJI & 432 & 2.5 & 16 & 0.21 \\
\hline
\end{tabular}

Table 1: Drone flights

Two different drones have been used during the acquisition periods. In 2016 and 2017, a Sony NEX-7 camera with 24 MPixel has been used, mounted on an Asctec Falcon 8.

For the 2018 flights, a DJI Mavic 2 Pro with the builtin 20 MPixel sensor was used.

The required ground control points were acquired using a differential GPS with $20 \mathrm{~cm}$ accuracy. Because of varying weather and time constraints, the number of measured GCP points varied between 10 and 22 (Table 1). Each drone flight was planned with a high image overlap of $80 \%$ and a height of $100 \mathrm{~m}$ and resulted in a ground resolution (GSD) of $2.3-2.8$ $\mathrm{cm}$.

\subsection{Orthophoto and Digital Surface Model}

From each drone flight, an orthophoto and a digital surface model (DSM) have been created using Agisoft Photoscan 1.4 (APS).

The external orientation within APS did achieve similar GCPerrors of 0.31 for 2016 and 0.33 for 2017. The slightly reduced error for 2018 (Table 1) can be explained by the increased image quality of DJI Mavic 2 camera. Although the DJI camera has a smaller pixel and image size than the SONY NEX-7, reduced optical distortion and improved color coating may be also crucial for the better orientation results.

For the generation of the three Orthophotos and DSM models, the same image matching and reconstruction parameters have been used within the ASP interface to build the dense cloud.

Quality :

Depth filtering: moderate

Surface type: height field

\begin{tabular}{|l|c|r|r|}
\hline Year & $\begin{array}{c}\text { Resolution } \\
\text { [cm] }\end{array}$ & $\begin{array}{c}\text { Dense cloud } \\
\text { [Megapoints] }\end{array}$ & $\begin{array}{r}\text { DSM Density } \\
\text { [points/m2] }\end{array}$ \\
\hline 2016 & 4.72 & 214 & 449 \\
\hline 2017 & 5.69 & 188 & 309 \\
\hline 2018 & 4.97 & 190 & 406 \\
\hline
\end{tabular}

Table 2: DSM generation

For all 3 years the resulting DSM show a sufficient resolution and related point density for the tracking of rock features (Table 2).
The DSM and the generated orthophoto of the test site contain enough level of detail for the required tracking (Fig 2. and 3).

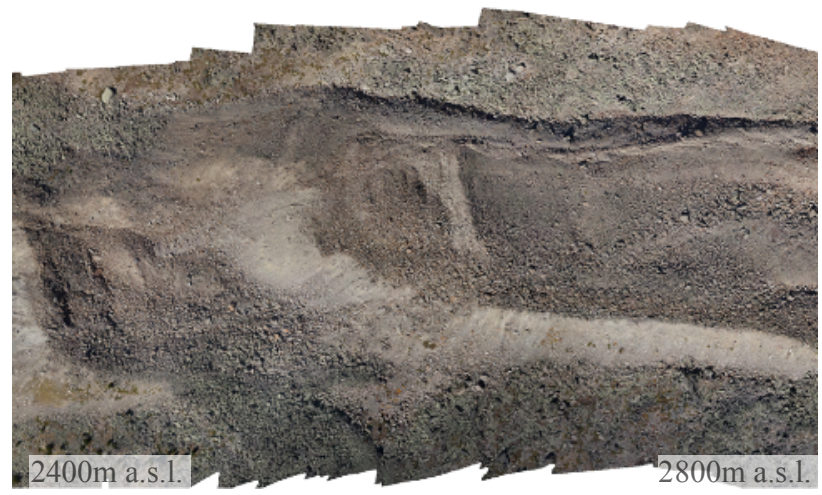

Figure 2. Orthophoto of test site Jegihorn.

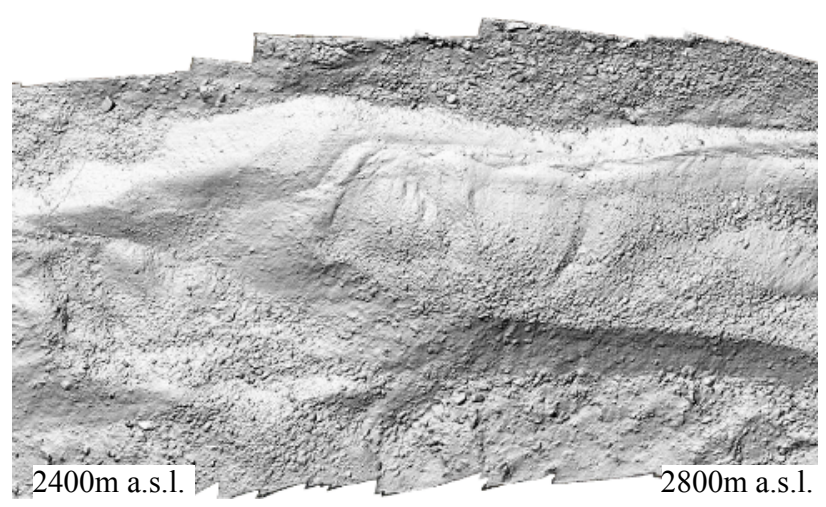

Figure 3. DSM of test site Jegihorn

\section{PROCESSING}

Normalized cross-correlation has often been used for the motion detection of photogrammetry-based flight campaigns over rock or ice glaciers (Debella-Gilo et al. 2012, Kaufmann 2012). But template based matching is highly sensitive and defining appropriate templates of varying natural surfaces is problematic. An improved extension to the template based approach using least square matching does not remove the intrinsic problem of template matching in natural environments (Maas et al. 2013). Rock glacier surfaces are characterized by a mix of stable bigger rock fragments and many overturned rocks and debris. The presented test site is typical mix of more or less homogenous flow areas and steeper formations, where rocks typically overturn within months.

Therefore we favor computer-vision based tie point matching for motion detection of mass movements due to several advantages. First of all, tie point matching with underlaying established algorithms like SIFT or SURF, rely on edge detection methods (Arandjelovic et al. 2012, Hartmann et al. 2016). The detection of gray level differences is much more robust than area-based template matching. Second, areas with different movement characteristics can be processed successfully, because tie point matching allows to detect movement of distinct rock corners. 


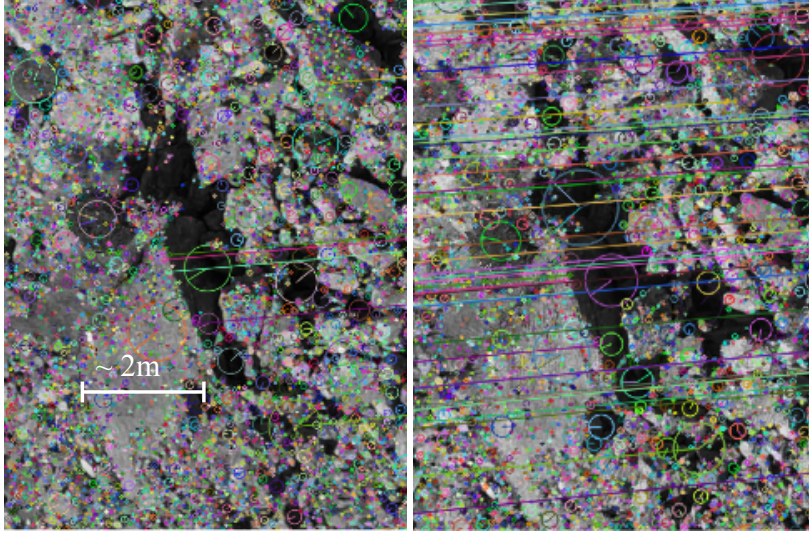

Figure 4. OpenCV Tie point matching (SURF)

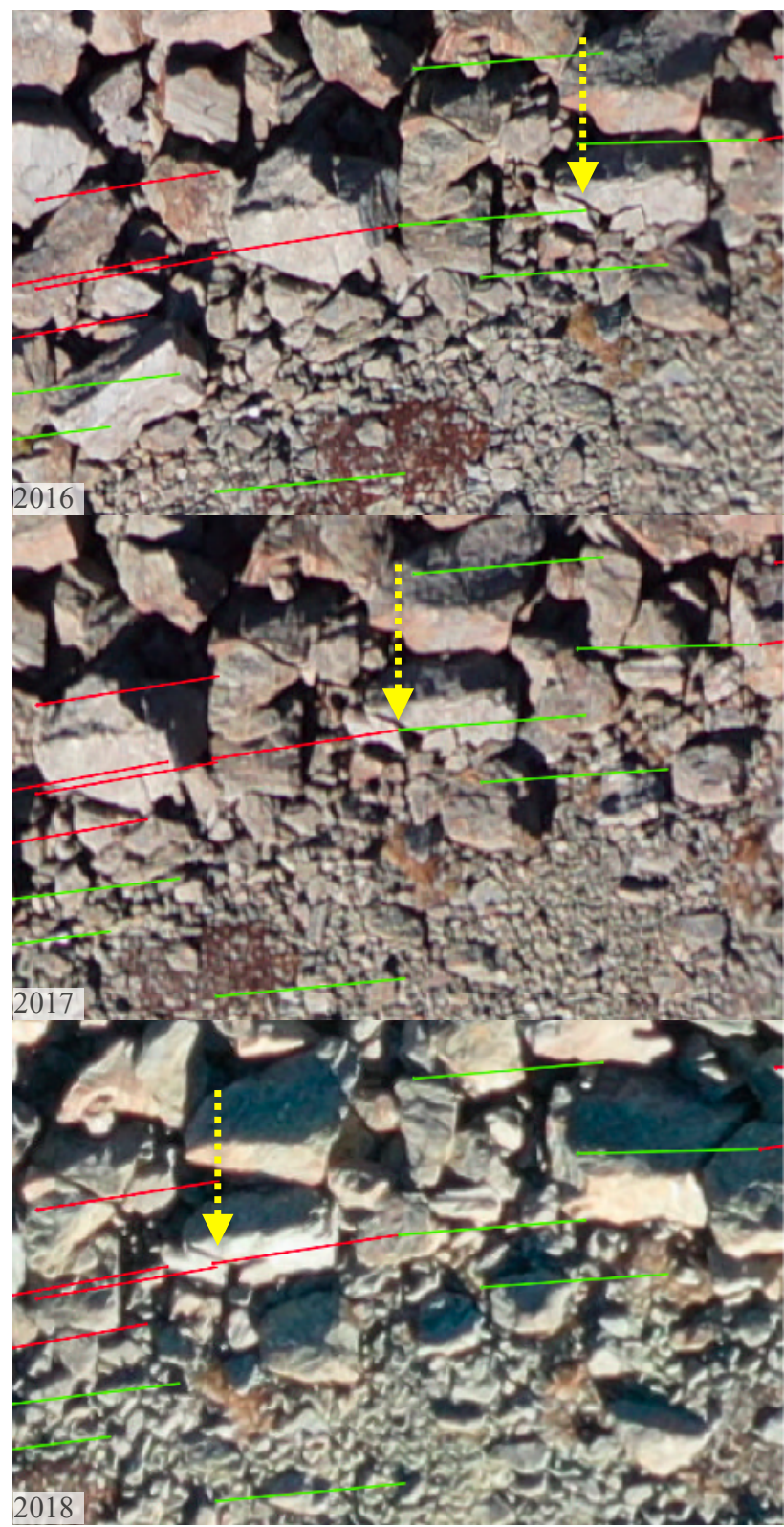

Figure 5. Tie point matching detail 2016, 2017 and 2018 green: 2016-2017 red: $2017-2018$

\subsection{Tie point matching}

Using OpenCV implementations (OpenCV 2018) for calculating tie point matching with the option for drawing rich keypoints, Fig. 4 shows a typical matching situation for the test site.

Precise motion tracking of the same single rock corner over the 3 time periods can be observed only in very few cases (yellow arrow in Fig. 5). If the upright position of the rock corner has not changed over 3 years, then a continuous movement can be measured.

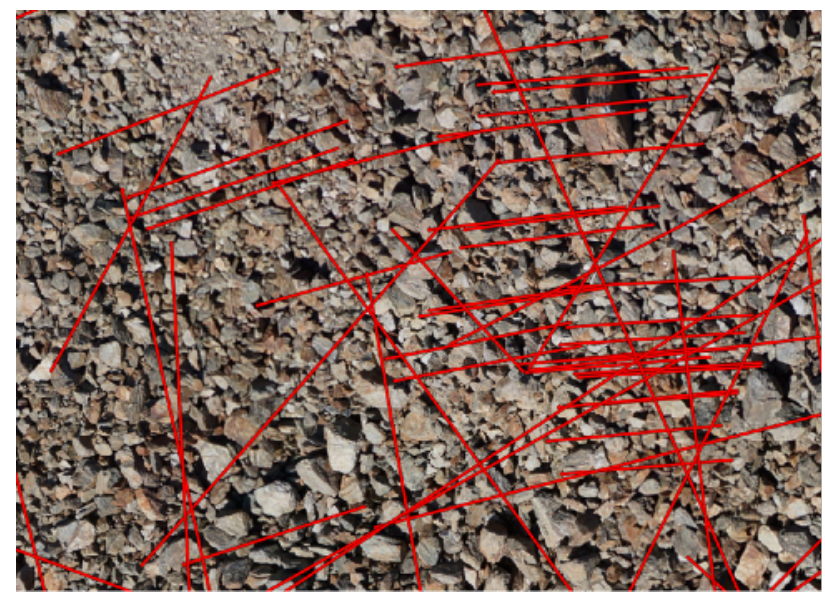

Figure 6. Tie point matching 2017-2018

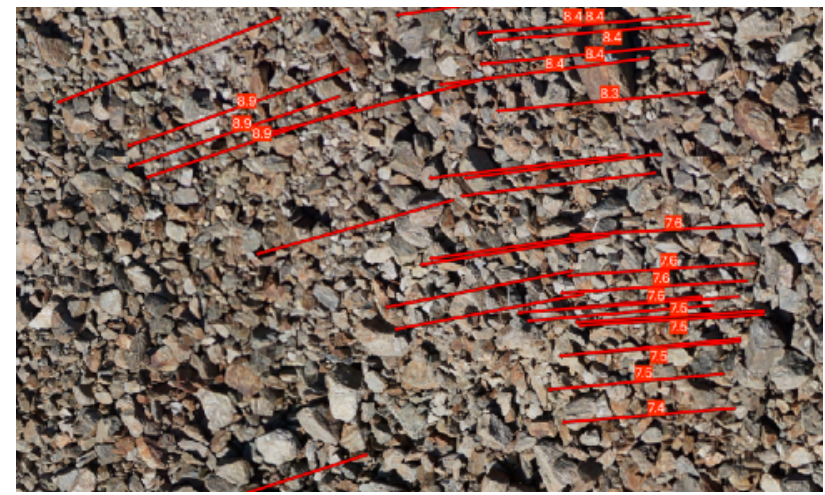

Figure 7. Local optical flow filter for tracked movements between 2017 and 2018

red values [meter/year] show robust movements

The initial tie point matching reveals a mix of appropriate and wrong assignments (see Fig. 6) for the comparison period 2016-2017. Similar results are found for the period 2017-2018.

\subsection{Filtering}

Many tie point connections are wrong, but unavoidable with the selected matching methods. In contrast to man-made objects, typical imagery of rock glaciers contain far less distinct edges.

But analyzing groups of tracking movements allows to filter misleading rock movements as far as enough neighboring movements with a similar direction and speed are found. Therefore a filtering of the found tracking movements is required (Fig. 7). 
Similar to optical flow considerations in computer vision, where flow is essentially constant in a local neighborhood, the following conditions have to be fulfilled (in pseudo-code):

1. tracked movement is less than $10 \mathrm{~m} / \mathrm{year}$

2. tracked direction is between 225 and 315 degrees

3. within $7 \mathrm{~m}$ radius at least 5 similar movements are found

4. standard deviation of $(5+1)$ tracked directions is less than 5

If all conditions are valid, the tracked movement is classified as robust.

The selected parameter values have been found empirically, the expected flow direction (225-315 compass degrees) is indicated by the given topography.

\section{RESULTS}

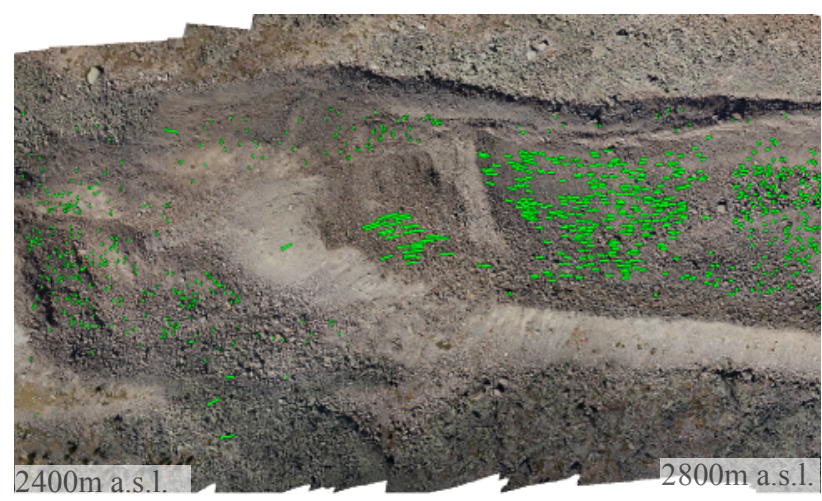

Figure 8. Tracked movement for the test site green: 2016-2017

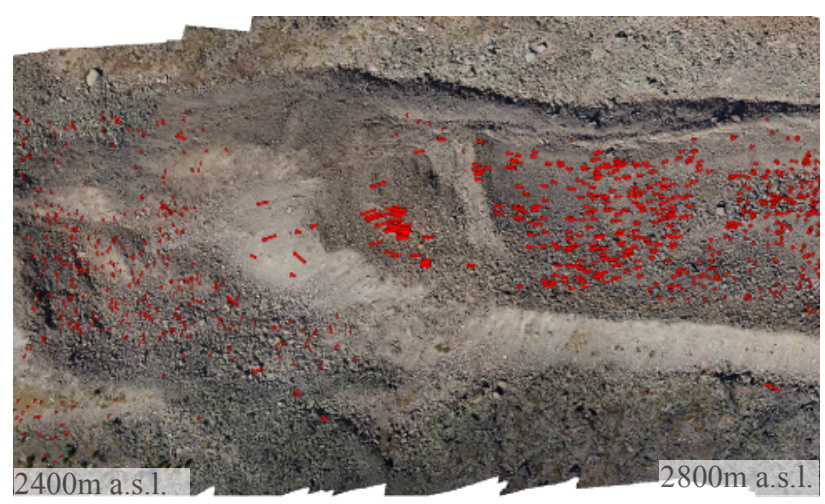

Figure 9. Tracked movement for the test site red: $2017-2018$

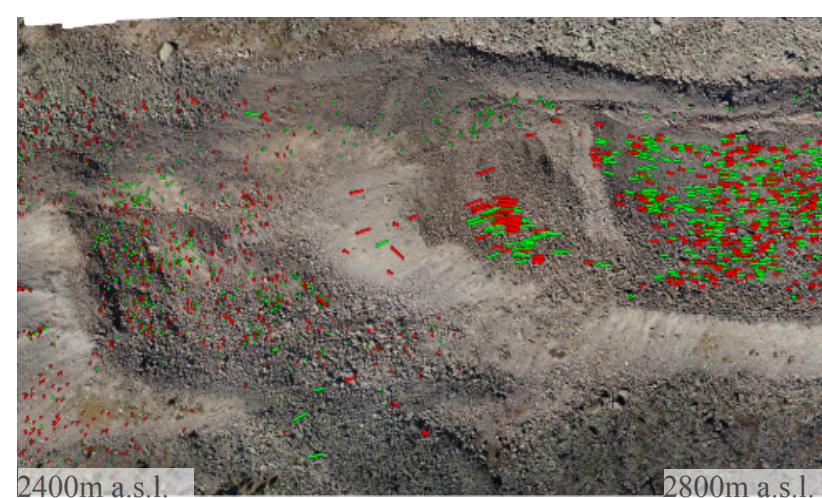

Figure 10. Tracked movement for the test site green: 2016-2017 red: 2017-2018

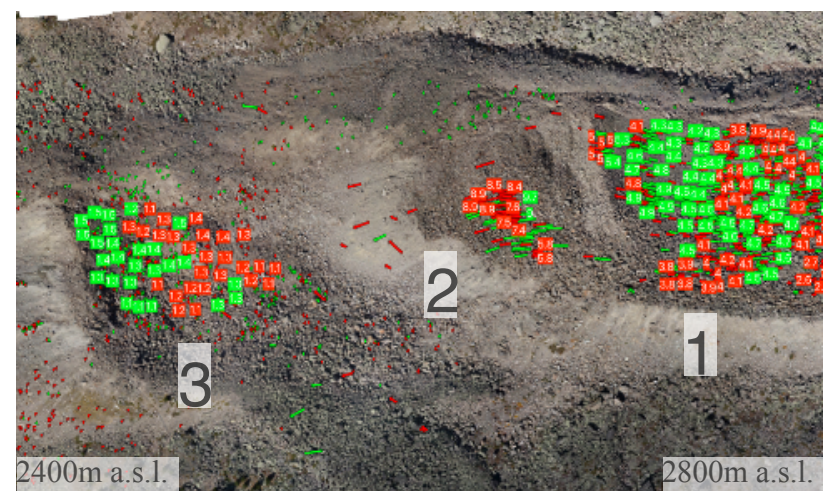

Figure 11. Tracked movement for the test site green: 2016-2017 red: 2017-2018 coloured values represent meters/year

Different movement areas can be identified (Fig. 8-11). In general, the movement within both year periods remains fairly constant, but the estimated speed is rather different.

In the upper part of the rock glacier (Fig. 11 Cluster 1) a steady flow of $4 \mathrm{~m} /$ year can be reliable estimated. Cluster 2 has an increased flow of $8-9 \mathrm{~m} / \mathrm{year}$, which could be explained by hidden melting ice bodies and rock structures in the underground. Cluster 3 at the front of the rock glacier is the slowest area $(1.5 \mathrm{~m} /$ year), mainly due to the reduced terrain slope above the distinct change in inclination at $2400 \mathrm{~m}$ a.s. 1 . This lowest section of the rock glacier also seems to be kind of decoupled from the upper part and is now slowly overrun by the upper part. 


\section{CONCLUSIONS}

Drone based image acquisitions over years are often conducted with varying equipment mainly forced by the fast ongoing development. Newer generations of commercial off-the-shelf drones like DJI Mavic are cost-effective, lightweight and still have a sufficient pay load reserve for flights at 2800 m.a.s.l. This allows that a two men crew can carry the necessary reference and drone equipment in a high alpine environment and a flight campaign can be conducted within one day.

Using different cameras with similar optical resolution allows to generate DSMs with comparable accuracy. The DSM resolution should be $10 \mathrm{~cm}$ or better to achieve enough robust tie point matching.

Tracking rock movements with tie point matching algorithms SIFT and SURF combined with an appropriate filter method allows to distinguish different movement patterns within local neighborhood. Nevertheless hidden melting ice bodies and steep terrain are the reason for frequent surface changes, which cannot be tracked reliable with tie point matching. A sufficient amount of rock parts with a persistent upright position is still required.

Using only one image acquisition per year is sufficient to capture average directions and surface velocities of a rock glacier. Seasonal differences in the displacement rate are not detectable.

\section{REFERENCES}

Arandjelovic, R. and Zisserman, A., 2012. Three things everyone should know to improve object retrieval, 2012 IEEE Conference on Computer Vision and Pattern Recognition (CVPR):2911-2918.

Debella-Gilo, M. and Kaab, A., 2012. Measurement of Surface Displacement and Deformation of Mass Movements Using Least Squares Matching of Repeat High Resolution Satellite and Aerial Images, Remote Sensing, 4(1):43-67.

Ghirlanda, A., Braillard, L., Delaloye, R., Kummert, M. and Staub, B., 2016. The complex pluri-decennial and multiphasic destabilization of the Jegi rock glacier (western Swiss Alps): historical development and ongoing crisis, XI. International Conference On Permafrost (F. Günther and A. Morgenstern, editors), Bibliothek Wissenschaftspark Albert Einstein, Postdam, Germany, pp. 36-38.

Hartmann, W., Havlena, M. and Schindler, K., 2016. Recent developments in large-scale tie-point matching, Isprs Journal of Photogrammetry and Remote Sensing, 115:47-62.

Kaufmann, V., 2012. Detection and Quantification of Rock Glacier Creep Using High-Resolution Orthoimages of Virtual Globes, XXII ISPRS Congress, Technical Commission V, 39B5:517-522.

Maas, H.G., Casassa, G., Schneider, D., Schwalbe, E. and Wendt, A., 2013. Photogrammetric Techniques for the Determination of Spatio-temporal Velocity Fields at Glaciar San Rafael, Chile, Photogrammetric Engineering and Remote Sensing, 79(3):299-306.

Muller, J., Vieli, A. and Gartner-Roer, I., 2016. Rock glaciers on the run - understanding rock glacier landform evolution and recent changes from numerical flow modeling, Cryosphere, $10(6): 2865-2886$

OpenCV, 2018. Open Source Computer Vision, URL: https:// opencv.org, (2018). 